The use of learner-generated drawings in the development of music students' teacher identities

Author details:

Associate Professor Dawn Bennett

Senior Research Fellow

Curtin University of Technology

Building 209/419

GPO Box U1987

Perth Western Australia 6845

Telephone +61 892664482

Facsimile +61 892663818

Email d.bennett@curtin.edu.au

This article is submitted exclusively to the International Journal of Music Education and, if accepted for publication, it is agreed that it will become the copyright of the International Society for Music Education. 


\title{
The use of learner-generated drawings in the development of music students' teacher identities
}

\begin{abstract}
The purpose of this article is to examine the professional growth of music students in relation to developing teacher identities. The article reports on the use of learner-generated drawings and journal reflections produced by music performance and education majors. In particular, the article probes students' perceptions of teaching within a traditional career hierarchy that favours performance and artistic creation. Student drawings produced for the project initially illustrated traditional images of the teacher as knowledge giver; however these gave way to student-centred images in which students appeared to identify with teaching in new ways. The combination of textual and non-textual data provided insights that would not otherwise have been evident, and the consideration of 'possible selves' became a useful tool in the exploration of identity and career.
\end{abstract}

\section{Key words}

Learner-generated drawings, identity, career, music, arts

\section{Background}

Clear self-image and ownership of an emerging professional identity are essential attributes for any novice seeking to successfully integrate program knowledge into a workplace situation (Calderhead \& Robson, 1991). However, identity development can be particularly problematic for musicians and other artists. Identity construction is a continuous process informed by hermeneutic self-understanding and social interaction. As such, it benefits from the acceptance of significant others, social groups and community. Inconsistencies between lived experience 
and stereotypical images of the artist as creator or performer can inhibit exploration of self and career. They can also threaten open discussion in which students might contradict or question these idealised social constructs.

Demystifying students’ perceptions of musicians’ work is a challenge faced by educators world-wide. The need for generic and specialist skills beyond performance has resulted in widespread debate about the nature of work and the structure of performance-based curricula (author; Carruthers, 2008). Indeed, many conservatoires and universities have introduced programs to develop skills such as those required to teach effectively. Whatever the extent to which pedagogy is incorporated into students' learning, there are crucial decisions to be made about what to include and how to teach it. An obvious and often primary concern is how to incorporate sufficient information and tools to equip students for teaching roles, and this is problematic not only for performance majors but for those majoring in music education.

A common approach within time-constrained units is to focus on theoretical concepts and methodologies; however, Brand and Dolloff suggest that this 'is often at the expense of actually helping music education majors to become teachers who are prepared for the complexities and realities of music teaching' (2002, p. 28). Even within general teacher training, Kagan (1992) suggests that methodological knowledge is insufficient unless students can experience the teaching environment and, by doing so, begin to take ownership of their teaching styles and their teacher identities. A further consideration in the case of music is the role that pedagogy training might play in the development of career and identity among students for whom teaching is perceived as a fall-back position. Miller and Baker (2007) suggest that pedagogy training is vital in this regard and can 'serve as a catalyst for changes in career orientation' (p. 5).

Against this background the project explored possibilities that exist within pedagogy units that encounter myriad limitations. These can include low status and contact hours; alignment with other elements of the curriculum; and the capacity to organise school- or studio- 
based experience, in turn limited by staff and student time, student motivation, course structure, and the absence of the pedagogical knowledge required by students to access a formal practicum. Whilst on-the-job and off-the-job training are influential, simulated practice can be the most feasible way to provide students with meaningful experiences within these limitations. Hence, the study sought to ascertain the value of simulated teaching and learning by enabling music students to combine the Aristotleian concepts of technical knowledge, which cannot be fully described in the form of written text; and practice knowledge, which cannot be 'reduced to simple descriptions' (Eraut, 1985, p. 119).

\section{Constructing multiple identities}

Professional identity is of special interest to those researching artist careers, and there is little research into graduate transitions and career development where entrepreneurship is the outcome of existing employment poverty (Greene \& Saridakis, 2008). Whereas for many people professional identity and job title are one and the same, the reality of life as an artist is the incorporation of multiple employments and complex working arrangements (Bridgstock, 2006). As a result, many artists have a career identity that does not correspond with their income sources (Mills \& Smith, 2002; Rogers, 2002). Self-definition as a musician, for example, could relate to work in performance, teaching, audio engineering, administration and research; and to waged or unwaged work unrelated to music. In these careers types, professional identity often encompasses multiple identities that are ideally applied according to task; however, 'the concept of a plurality of occupational identities is engaging in theory but a challenge to maintain in practice’ (Bain, 2005, p. 42).

Bain describes the mythological figure of the artist as having been 'variously constructed' (2005, p. 28) throughout history, existing away from the capitalist world economy and related to genius, isolation and eccentricity. The aspect of isolation conjures up specific difficulties because, whether or not work is defined in terms of salaried activity, it is a means of 
participatory belonging and it is central to personal identity and self-image. Similarly, music education majors can come to tertiary training with fantasised notions of teaching derived from film, television, books and their own lived experience, and resulting in what Weber and Mitchell call a 'kaleidoscopic collage' of images (1995, p. 128). This raises the question of how and when students should begin to examine mythologies within the context of their own strengths and interests, established hierarchies, and “possible selves” (Marcus and Nirius, 1986).

During the period of professional training, Harré (1984) describes a continuum of identity development from individual to personal, collective and, finally, social. Over the course of the continuum, individuals look increasingly outwards for affirmation of their identities. For music performance majors, initial sources of this affirmation are role models such as professional performers and "master" teachers who 'provide a mirror to the identity under construction' (Huhtanen, 2008, p. 4), and who are likely to see 'most aspects of their lives in relation to music: their musical activities are at the core of their self-identities' (Hargreaves \& Marshall, 2003, p. 264). At odds with this worldview is students' growing awareness of the competitive and diverse nature of careers in music (Burt-Perkins \& Mills, 2006).

For multiple identities to co-contribute to an intrinsically satisfying career, artists need to consider their careers both subjectively and objectively. The role of teaching within music careers is an excellent example of how the same activities can be deemed successful by one person and unsuccessful by another. For example, a musician who is teaching as a means of financial support whilst aspiring to a performance career is likely to have a subjective career as a performer rather than as a teacher. Conversely, someone who views teaching as a positive longterm career activity is likely to have a subjective career identity that concurs with their objective one. Huhtanen (2004) describes these two cohorts as dreamers and realists. It follows that intrinsic career satisfaction, which is a primary measure of success within protean careers, correlates with the level of alignment between subjective and objective career identities. 


\section{Teacher development and performance majors}

Multiple theories of teacher development were considered in relation to the study and these are discussed throughout the paper. Kagan’s (1992) focus on pre-service and first-year teaching was useful with respect to the general student cohort in that it documents three crucial phases of development during this essential stage. Novice teachers, she writes, begin by acquiring knowledge about students. This knowledge is used in the construction of self-identity as a teacher, following which procedural routines are adopted for classroom management and instruction. Kagan concludes that pre-service programs and student practicum placements fail to adequately address these three steps. Rather, as novices move through these three phases they search first for self-affirmation as teachers before focusing outwards to students and, eventually, to student achievement as an external validation of teacher competence. Ryan's (1986) theory of teacher development similarly moves along a continuum from mythologised notions of teaching to survival, then to mastery of tasks and, finally, to the impact of teaching on students.

The difficulty with performance majors in the early stages of their training is that selfidentity is likely to be narrowly defined in line with the priority afforded to performance ambitions. Because the reality of life as a musician involves activities beyond performance, students' performance identities go only part of the way towards the need for them to 'develop their own authentic voices at the outset of their professional education' (Beattie, 2000, p. 17). Although many music students anticipate the inclusion of non-performance activities within their careers (Burt-Perkins, 2008), the adoption of these activities as part of their long-term identities is much less certain.

Existing career development theories commence after the decision has been made to pursue a vocation at a professional level. Because performance majors have often not considered teaching in relation to their future careers, they appear to be a fundamental step behind the theoretical continua. As a result, this study drew on what Huhtanen (2008) describes as a "personal interpretive horizon" to investigate ways in which students can begin to ultimately 
rewrite their horizons and reach the first step of broader career development: to 'adapt the provided tradition and shape his or her identity to be, not a copy, but a genuine one' (p. 5).

\section{Method}

Twenty students (14 female, 6 male) participated in the project, which was implemented as part of a twelve-hour pedagogy unit. Four of the students were undertaking a music education degree to become classroom music teachers, and the remaining students were performance majors. The unit represented the only compulsory pedagogy training for the performance majors.

As discussed in the background, an essential aspect of teacher development is the opportunity for students to 'experience cognitive dissonance and question the appropriateness of personal images and beliefs' (Kagan, 1992, p. 150); thus the unit was structured to ensure a lowrisk environment within which experimentation, self- and peer- review and reflection were encouraged. Students engaged in a diverse range of activities. Peer teaching was an important element of the class, and each student gave and received at least six individual instrumental or vocal lessons. Students also presented to the class two five-minute teaching sessions that included a pre-determined goal, delivery of content and summary of learning. The first session could be on any subject with which the student felt comfortable. As a result, the class learned a variety of skills including how to stand up on a surfboard, how to lift weights safely, and how to perform a rhythm holding four mallets. The unexpected arrival of an audit team during the surfboard lesson was a particular highlight for the students.

Throughout the unit there were numerous activities which encompassed communication, planning, risk taking (such as teaching something newly learned), performance stress, group work, teamwork, and approaches to teaching and leaning involving movement and creative tools such as graphic scores or improvisation. The common factor was that every activity engaged students in both active teaching and learning, so that they were experiencing the different ways in which they and their peers learned, and were applying this continuously to their teaching. 
Taking a hermeneutic approach to generative self-conscious interpretation, Ellis (1998) used learning journals with pre-service and graduate students to examine pedagogic relationships within practicum projects. She concluded that this kind of dialogue results in a 'fusion of horizons' (p. 8). For this study, data collected over two semester-long classes were drawn from reflective journals, surveys and drawings. A reflective journal was the central device for recording both teaching and learning activities, and students were able to choose the format of their journal. Although most students used a notebook and wrote by hand, two submitted electronically. Many students made attachments or linked their writings to other sources of information. Every activity, including each individual teaching or learning session, attracted a peer-assessment and self-assessment that were recorded in the journals, and reflections were ongoing. Peer reviews did not have to be shared in their written form; however, students developed the skills to integrate generalised critical feedback into group discussions, and to give negative feedback in a constructive manner.

Drawing on Britton’s (1977) concept of play together with Bruner’s (1987) writing on narrative, Creme (2008) argues that journals can enable students to access a potential or transitional space incorporating both play and creative activity. These elements were of specific interest to the study and resulted in the engagement of a modernist view of hermeneutics incorporating both text and non-text based learner-generated materials, the latter described by Van Meter and Garner (2005, p. 289) as 'the learner's representational depiction on paper of the image experienced internally', and for which the learner is primarily responsible. On the basis of artistic expression being 'the spontaneous expressions of ordinary people' (McNiff, 1997, p. 39) rather than a specialist activity, the use of drawings with students who were not visual artists was a deliberate attempt to steer away from the more traditional forms of questioning in relation to self-awareness and professional identity. However, the study took into account the limitations posited by VanTilburg (1987) and by MacPhail and Kinchen (2004) who observed that although 
drawings are a valid and useful means of data collection they can represent subjective prejudices and interpretations. Drawings were, therefore, combined with other forms of data collection.

A two-part survey was implemented at the commencement and the end of the unit. The initial survey asked students about their expected and desired careers and the anticipated role of teaching. The final question asked students: 'Please draw a teaching situation'. At the end of the unit, students answered a second survey in which they reflected on their perception of teaching and the value of tools and activities within the unit. The students were given a sealed envelope containing their original drawing and were again asked to draw a teaching situation. In addition to questions about students’ background and experience, survey questions included:

\author{
What is your number one career goal? \\ Why did you choose this elective? \\ What would you like to get out of the unit? \\ Do you expect to teach after university? \\ Why will you teach? \\ What form/s will your teaching take? \\ Please draw a teaching situation (both surveys) \\ Has your perception of teaching changed? If so, how? (Survey two) \\ In what ways has the reflective journal influenced your thoughts about teaching? (Survey two)
}

Drawings were analysed by individual student response, performance or education cohort, and the whole class. Pseudonyms are used throughout the paper to ensure participants' anonymity.

\title{
Results and discussion
}

\section{Why will you teach?}

Given the hypothesis that performance majors are not yet at the "first step" of career development theories with respect to teaching, it was necessary to gauge student perceptions of teaching prior to the unit. This information was sought within the initial survey. The data were 
analysed in two student cohorts with a focus on two pertinent survey questions: 1) 'Do you expect to teach after university'; and 2) 'Why will you teach?' The first cohort $(n=7)$ included the music education majors. Also in this cohort was one student who wished to pursue music therapy and one who wanted to train in arts management. Not surprisingly, the students who cited teaching as their primary career goal all expected to teach, and they nominated a combination of instrumental and classroom teaching roles. Asked why they would teach, responses from the first cohort commonly centred on a desire to teach and a passion for the subject: 'I want to teach to help others love music' (Roy). Many of the comments also suggested the adoption of a teacher identity: 'I love it. It’s what I want to do’ (Linda).

The second cohort $(n=13)$ included the performance majors. Performance majors are likely to embark upon performance-based training in search of performance careers (Presland, 2005), but through the course of their undergraduate studies they tend to become increasingly aware that their careers will involve other activities such as teaching (Miler \& Baker, 2007; Mills, Burt \& Moore, 2005). As anticipated, all of the students expected to teach; however, the anticipated role of teaching within the performance majors' careers became more apparent from their responses to the question, 'Why will you teach?' Although three respondents mentioned enjoyment and four mentioned sharing musical knowledge, all but one of the responses positioned teaching as a supporting role separate to the performer identity: for example,

$\begin{array}{ll}\text { Jessie } & \text { 'To support income from performance' } \\ \text { Suzie } & \text { 'Probably I'll have to, rather than wanting to pass on skills/knowledge' } \\ \text { Caroline } & \text { 'Yes at some point, but I don't want it to be my main priority' } \\ \text { Paula } & \text { 'It’s a good thing to be able to do on the side’ [student emphasis] } \\ \text { Jordan } & \text { 'Teaching kids would be fun and a good side job' } \\ \text { Ken } & \text { 'Source of income' } \\ \text { David } & \text { 'To earn money and give kids the right advice' } \\ \text { Liz } & \text { 'For money reasons' }\end{array}$


Responses from the performance cohort illustrate that teaching is often viewed as a fallback option reminiscent of Huhtanen's notion of dreamers and realists. The implications of this include musicians who teach without having accepted teaching as a successful and intrinsically satisfying component of their careers; the perpetuation of existing hierarchies; and graduates whose level of performance focus has left them feeling unprepared to adopt and effectively manage a teaching role. It was hoped that the unit would broaden students' perceptions of teaching without dwelling on the almost inevitability of their future engagement with teaching.

\section{Drawings}

Brand and Dolloff (2002, p. 18) describe drawings as metaphors that 'are containers for our thoughts and reflect our personal stories'. As many of the students were performers and had not necessarily made an active decision to teach, they were asked to draw a teaching situation rather than to draw themselves. Within the students' drawings, people were largely represented by stick figures or symbols and initial drawings were typified by traditional images of the teacher as knowledge-giver (Weber and Mitchell, 1995). Student drawings focused on teacher-student relationships and the composition of teaching spaces.

The open nature of the question enabled students to draw classroom or studio situations, or indeed both. Surprisingly, given that the unit had only twelve contact hours, comparison of initial and second drawings suggests movement along the career development continua described by Kagan and others. The drawings, when used in combination with journal reflections and peer review, provided a rich source of data.

Sue, a music education student, drew representations of both classroom and instrumental teaching. The most pronounced change between her initial and second drawing, shown together at Figure 1, was the rearrangement of her classroom space to reflect a more open learning environment with a large, central space for movement work. At the beginning of the unit, Sue reflected in her journal: 'according to lecturers, you are better off getting students physically 
involved in music, or they will think that it is a boring subject'. This line of thought was pursued throughout her learning experience: for example, her critical peer-reviews of three other students' five-minute teaching sessions included comments such as: 'I felt it was very much a lecture and honestly I wasn’t thrilled by it’; ‘...we had possibly tuned out of what he was saying as we were not involved in the lesson'; and, later on, '...it was not that interactive or using student-centred learning'. In the evaluation of her own first teaching session, Sue wrote: 'I had them in groups and they were finally doing something' [student emphasis], and in the equipment list for her second session she includes 'students willing to learn'.

Towards the end of the unit, Sue appeared to take ownership of the student-centred concept, writing in the first person of herself as a teacher. Rather than citing the views of lecturers, she now wrote:

It is really important that we as teachers get students actively involved in lessons so that they are physically taking more in and are more likely to relate to the subject matter, not allowing students to get bored so that the lesson is more interesting.

School students do not like being lectured at and this is a very distinct thing which happened in many of the 5-minute lessons, especially from those who were talking about their instrument. It was almost as boring as getting a history lesson.

In her final unit survey she concluded: 'basically, I am now thinking more like a teacher'.
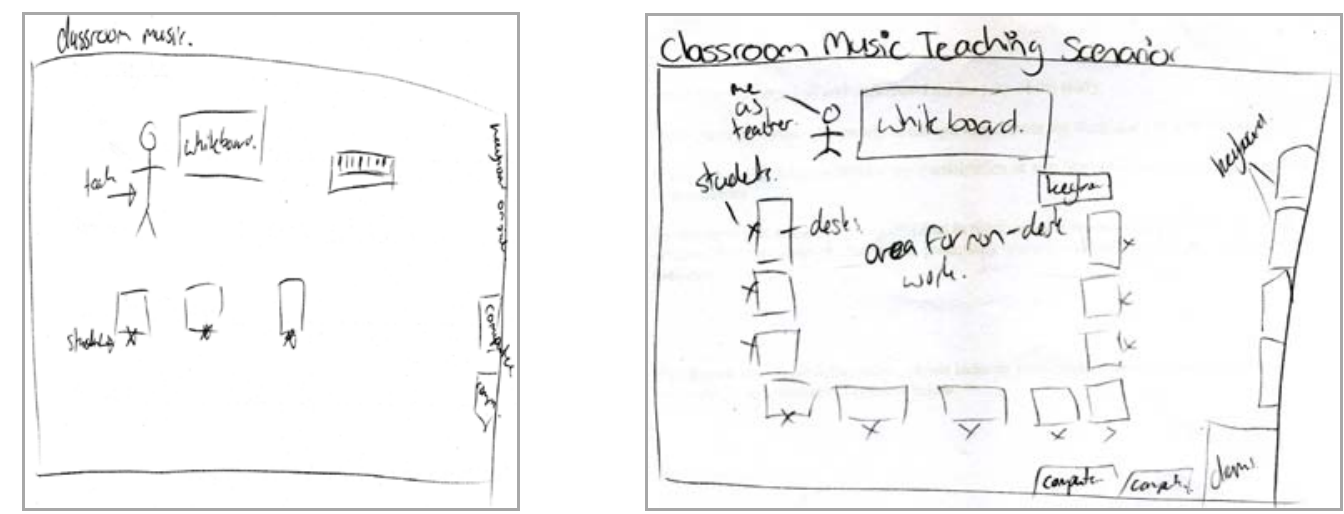

Figure 1: Sue’s initial drawing (left) and second drawing (right) 
Six of the performance majors cited performance as their primary career goal. For four of these students, performance was the only outcome listed. When asked in the initial survey why they had selected the pedagogy elective, three students focused on a desire to improve communication skills, three mentioned teaching skills, and one wrote about gaining confidence. Paula, one of the four students who had listed only a performance goal, wrote in her final survey that the unit 'made me look at myself as a teacher'. Her comments reflected a growing enthusiasm for teaching, which she had not previously considered a desirable career outcome.

Paula's first drawing separated teacher from student and weighted the teacher with a dark cross. In her final drawing the participants had been humanised and both teacher and students were wearing smiles. The teacher figure was the same size and shading as the students, and Paula labelled the configuration as a circle, which was a move away from the teachercentred configuration shown in the first drawing (see Figure 2). Diane, another performance major, drew a very similar configuration at the end of the unit and noted: 'I would like my lessons (my teaching) to be very different and fun, and allow the student to really interact and engage with the material instead of being lectured, all one-way’.
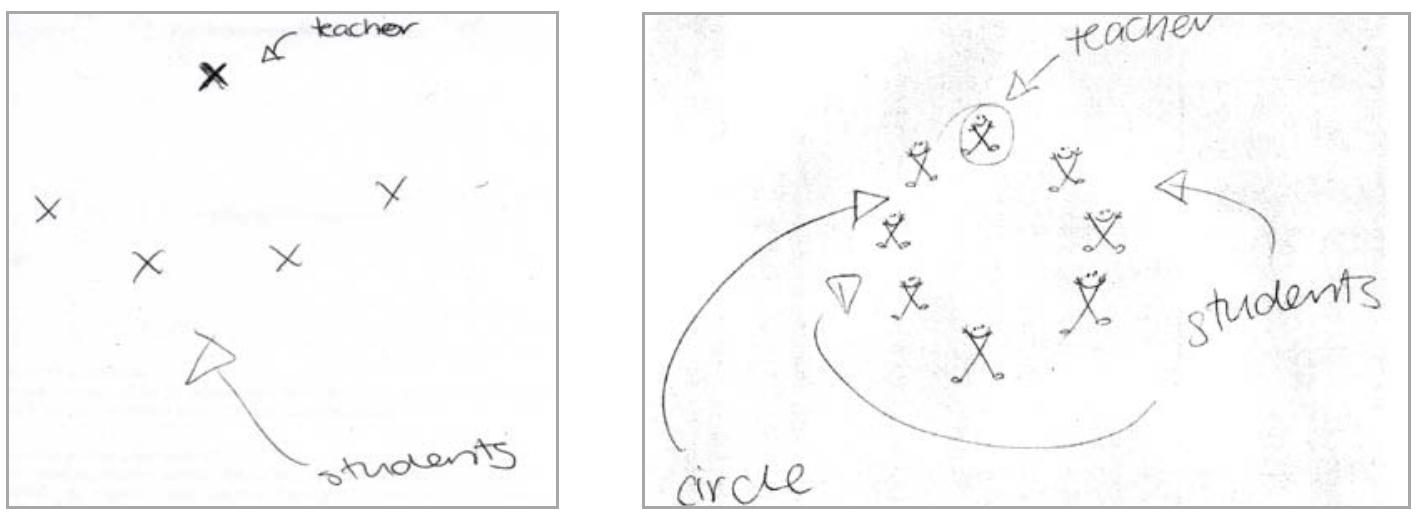

Figure 2: Paula's initial drawing (left) and second drawing (right)

Suzie, a performance major, was clear at the start of the unit that any teaching involvement would take the form of higher education lectures, which she represented with a tiered lecture hall. At the end of the unit her teaching focus remained at the tertiary level, but she had completely rethought the configuration of the space in which her teaching might take place 
(Figure 3). Although her second drawing suggests the continuation of a teacher-centred approach, it also suggests a progression from what LaBoskey calls an inward-focused 'commonsense' thinker to a student-focused 'pedagogical' thinker (in Loughran, 2006). Triangulation with her journal reflections and peer reviews reinforces this progression.
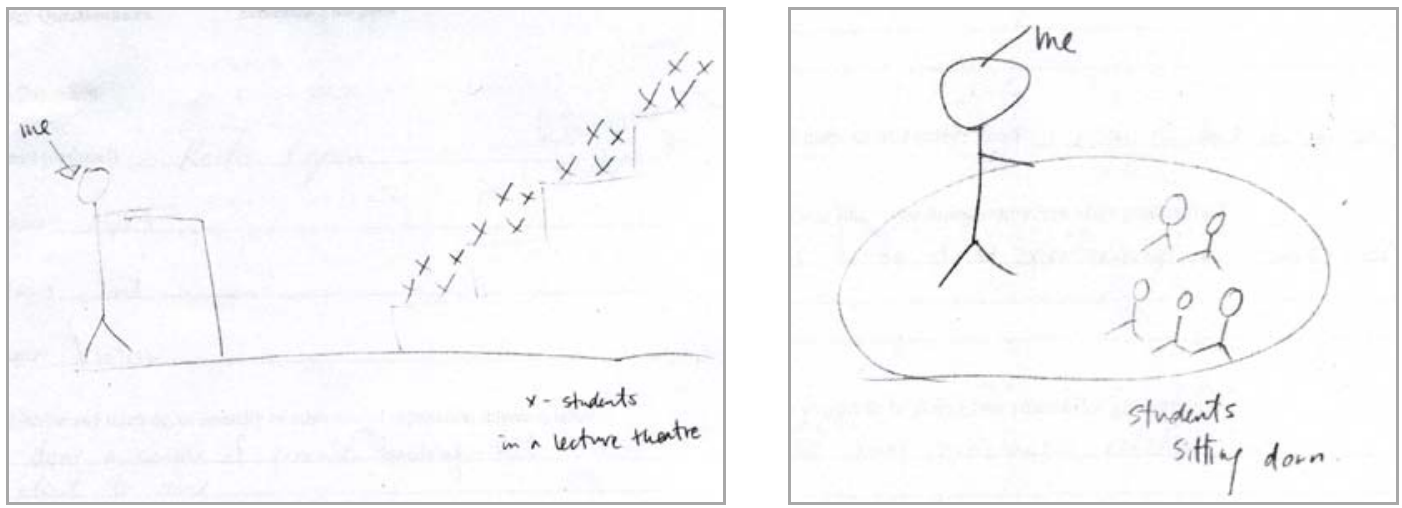

Figure 3: Suzie’s initial drawing (left) and second drawing (right)

The transition from teacher-directed to student-centred learning was also notable among the education majors. Of her first teaching session, one student (Linda) reflected: 'I do not think the class enjoyed the lesson. They were bored. They became more interested when I got them ALL to do things. ... Next time I will try to make it more engaging so they will have fun but also learn'. Linda took this into account when planning her second session, after which she wrote: 'I got the students active and made them part of the lesson'. In her first drawing, Linda portrayed an instrumental teacher listening to a student play, whereas in the second picture Linda portrayed teacher and student playing together. It is not possible in the second drawing to tell which figure is the teacher.

Of particular interest are the drawings of one of the performance majors, Graham, who took the unit for a second time despite having already passed the unit. A guitar major, Graham was initially a quiet member of the class who struggled to engage other students, and his drawings revealed fears and uncertainties that would not have been apparent from his journal writing alone. Similarly, the almost comedic nature of the drawings may well have been 
dismissed as larrikin had they not been cross-referenced with the other evidence. Analysis of his drawings (shown as Figure 3) together with his journals and the peer-reviews from his fellow students were very useful in understanding the hurdles he was facing. It was as though he had found, as Creme (2008, p. 62) writes, 'a rare space for meaningful play in the academic setting'. As discussed, the first survey asked students about whether and (if so) why they might teach. Graham demonstrated his interest in teaching in his initial survey response: 'I have a passion for music and the study of music. To be able to share that with students would be a fantastic career for me'. At first sight, his initial drawing appeared to position him in a disorganised classroom without having control. However, later in the unit his journal writing revealed that his picture represented an experience he had as a student:

I will not stand for any crap. I’ve seen first hand what it can be like to have a disorderly class.

My year 9 maths teacher had no control of his class, and students practically walked all over him. It was not a nice learning environment, and something I would not like to emulate!

These comments were journalled just before Graham's first peer-teaching session. In contrast to the first drawing, his end-of-unit drawing portrayed him teaching a class and having lost the students' attention. Graham's concerns about student engagement were realised in his unit activities and the theme permeated both his self-reflections and the peer reviews of his teaching. Prior to his third peer-teaching lesson he wrote that 'last week in comparison to the [instrumental] lesson Suzie gave me, my lesson was boring. I might try and make it more of an enjoyable experience by throwing in a few jokes'. The comedic approach, however, did not work in his class presentations. Another student noted in her diary: 'he tried to make a joke but nobody laughed. I think we had tuned out'. However, prior to the fourth peer-teaching lesson Graham made a huge step forward: 'Ultimately I want Suzie to feel she has some freedom with choice in her learning guitar. ... This will help to make Suzie's lesson more interesting next week’. Graham's initial second semester picture illustrated his strategy of giving students some 
freedom of choice within their learning; nonetheless the risks associated with this were clearly illustrated in the final picture.
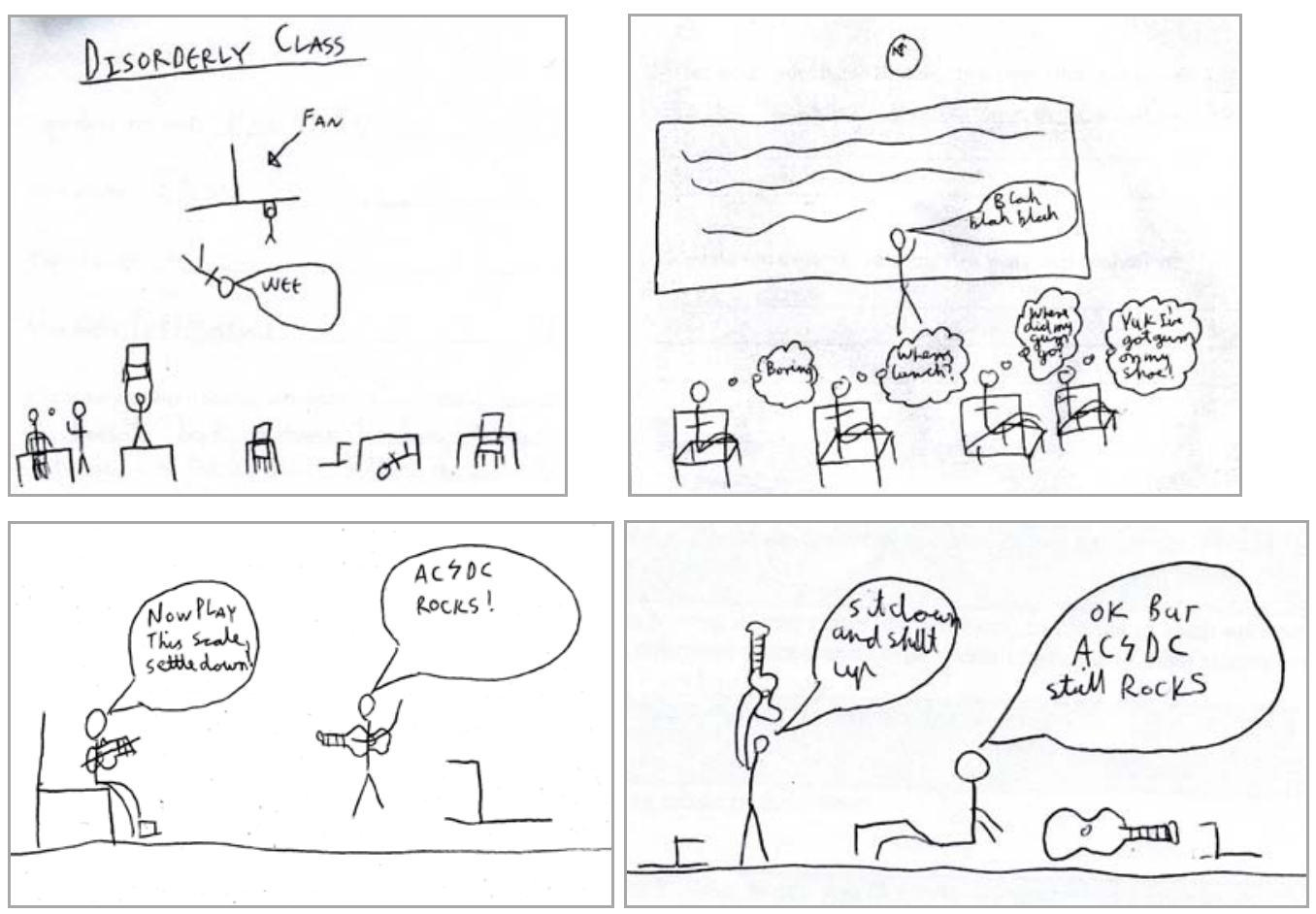

Figure 4: Graham’s drawings: Semester 1 drawing 1 (top left) and 2 (top right);

Semester 2 drawing 1 (lower left) and 2 (lower right)

Although the study sample was too small to make generalisations according to instrumental group, the students of guitar and piano wrote of more difficulties with the communication skills involved in effective teaching and learning. One of the piano majors, Caroline, struggled with the delivery of both five-minute lessons, and she reflected at the end of the unit that the most important experiences for her had been those involving the whole group: 'demonstrating to the class, learning from others, and discussing situations and finding solutions to resolve them'. Her rationale for selecting the unit had been to gain confidence.

Two of the vocal majors were clear about their intended careers, Karen as a performer and Liz in music business, and neither had considered vocal teaching. Karen acknowledged the likelihood of teaching 'to support ourselves whilst looking for work as performers'. However, she mused: 'I'm not sure how I feel about that, since I have always viewed myself as a 
performer, rather than a teacher'. Throughout the activities within the unit, the two students used the notion of play as transitional space to make meaning of this new potential by "trying on" ‘different ways of knowing and speaking’ (Creme, 2008, p. 61), often bouncing ideas off one another before bringing them to the whole group.

Liz was initially very blasé about the idea of teaching, but eventually she engaged in the group work and became an active member of the class. Her second five-minute lesson was interactive and very well planned, and she reflected that: 'When I started pedagogy I wasn't sure if I really wanted to do teaching, but now I'm thinking about it as a possibility'. Her drawings illustrated a progression from a simple, happy venture to one in which the business of teaching came to the fore. Liz didn't include herself or a student in her second drawing, despite being present in the first. When asked about this, she responded that teaching is 'not as easy as you think it would be'. Karen didn't produce a drawing at the start of the unit, but at the end she drew a detailed representation of a teaching space in which she focused on the necessary equipment. She didn't include herself or a student. At the end of the unit she reflected: 'My view of teaching has changed dramatically. I was always quite pessimistic about teaching but now that I know how to plan lessons, I feel more confident'.

Jane, the only other participant who did not produce a first drawing, was also a performance major. Commenting on the absence of a first drawing, she explained: 'Before, I couldn't see teaching in my head'. Jane came from a strict instrumental teaching system in Korea and her experiences of instrumental teaching were reflected in her journal as she wrote about her own teaching. Jane slowly began to engage with group activities and to gain confidence, and wrote about one activity: 'I was impressed that we were dancing to some music. I'll never forget it. Making new experiences is a good way to enjoy music'. New ideas and activities were transferred directly to her existing teaching practice and she began to comment on increased enjoyment among her students. Her end-of-unit drawing reflected her learning journey in a very positive way, with an illustration of music and fun. 


\section{Concluding comments}

Within their discussion on the motivations of school students to engage with music, Hargreaves and Marshall write that self-identity 'is an inextricable part of the process of development itself: thinking of oneself as a musician can be an important step on the road to becoming one' (2003, p. 272). However, thinking of oneself in terms of a performer rather than in terms of a holistic career in music_as a musician—is perhaps both professionally and personally limiting. Given the realities of practice as a musician and the considerable presence of teaching within musicians' portfolios, it is essential that students are encouraged to explore potential career paths and possible selves beyond traditional hierarchical constraints.

Performance majors come to tertiary study having been socialised as performers, and will often have been among the most accomplished performers within their peer groups; thus it is unsurprising that their identity (or existing "self”) is initially performance focussed. The performer identity has been promoted through performance-centred examination systems, labels of giftedness and even the competitive audition process for a university place. However, the early labelling of performers often results in the neglect of other strengths and interests and, because of the traditional career hierarchy, many students experience tension 'between the revelation of authentic identity to the self and the social meaning attributed to this in the presence of others' (Gibbs, Angelides \& Michaelides, 2004, p. 190). The common placement of pedagogy units as "supporting” studies, or as electives rather than core units, further reinforces social and cultural perceptions of success in which teaching is less successful than performance.

Musicians need to develop a positive self-identity in relation to their work, and the addition of a teacher identity would seem a pre-requisite to an intrinsically satisfying engagement with teaching (author, 2006). It has even been suggested that novices 'who enter the classroom without clear images of themselves as teachers are doomed to failure' (Kagan, 1992, p. 146), and yet there is a gap between existing teacher development theories and the cohort to which performance majors belong. Existing theories tend to commence their developmental 
continua after the decision has been made to become a teacher. They do not, therefore, fully represent the development of people who attend introductory teaching units as a component of unrelated studies, or who engage in teacher training because of a lack of other work. This includes many people who undertake graduate qualifications in education following completion of their undergraduate degrees, and it is important because it is acknowledged that the process of becoming a teacher begins early: Weber and Mitchell cite extensive research that has found ‘becoming a teacher begins long before people ever enter a Faculty of Education’ (1995, p. 5).

For students who have yet to identify teaching as a desirable or long-term component of their careers, this preliminary identity development has yet to occur, and they have not yet reached the starting point of existing developmental continua. The findings of this study suggest that "unintended teachers" such as performance majors may require an expanded developmental continuum. As such, Kagan's three phases of novice teacher development have been adapted and two preliminary steps added as follows:

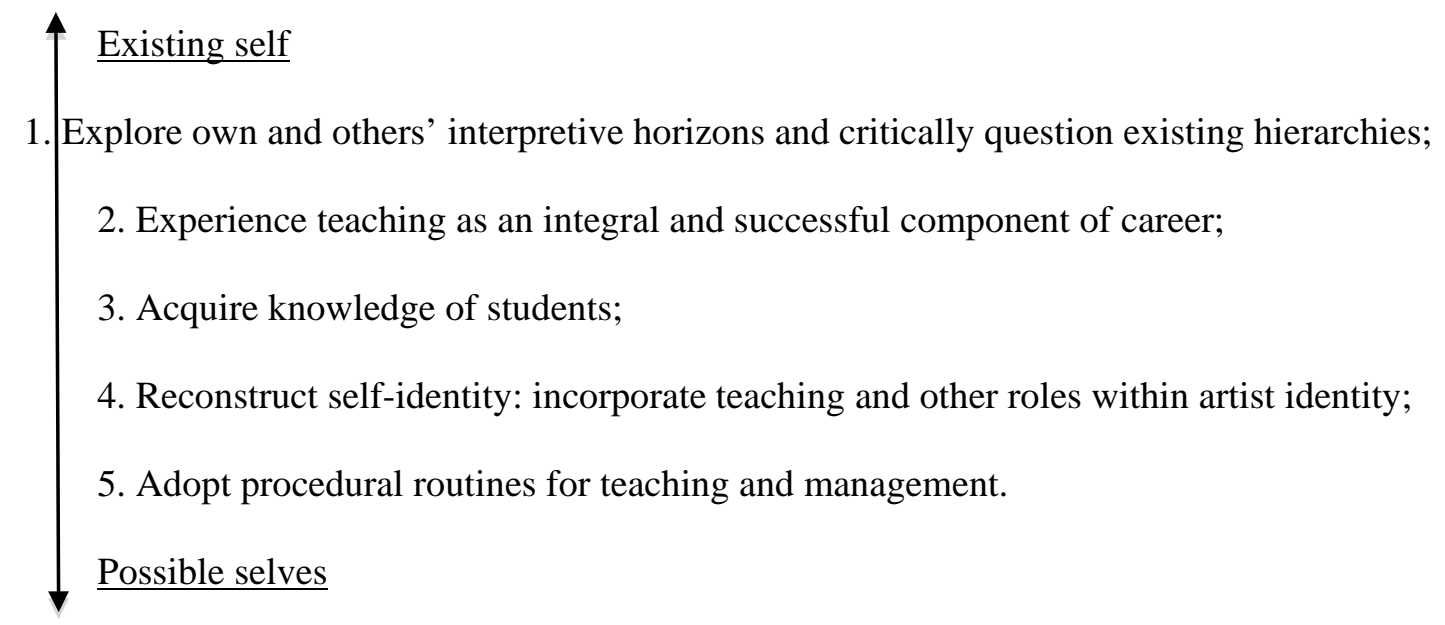

The process of music making and learning has for most students been a largely private venture, and simulated practice appears to link self-learning and professional practice so that participants can gain feedback and test emerging skills within an environment of guided peer- and mentor evaluation. Having engaged in the unit activities, students were more motivated to look at 'possible selves' within the interface between motivation and self-concept (Marcus \& Nirius, 
1986) and to consider teaching activities as both an integral and positive component of their composite musician identity. Reflecting earlier discussion about the methods focus of initial education classes, the benefits of the practical application of skills were also felt by music education students who gained confidence and began to take ownership of their teaching. The education majors increasingly applied methodological terminology to their self-assessments, planning and peer-assessments, and one education student directly related the benefits of the simulated practice to her forthcoming practicum placement: 'I feel more confident about going on prac next semester from doing this unit than through my education units’ (Sue).

For musicians to be intrinsically satisfied with their teaching roles they must own their teacher identities, and there is a world of difference between doing an activity and owning the identity associated with that action. As Bowman (2004, p. 30) points out, mind 'is inextricably biological and embodied; and what it can know is always grounded in the material and experiential world'. The combination of open discussion, self-reflection, peer evaluation and simulated practice provided students with a springboard for discussion. Reflective journals gave students the freedom to write subjectively and non-academically, and the combination of textual and non-textual data stimulated self-reflection that may not otherwise have been possible. The most valuable shift for participating students was that by "doing” the activities of teaching they began to think of themselves as "being” teachers. This was seen in their eventual use of phrases such as 'we, as teachers...' and 'as a teacher I am...' The results suggest that even small pedagogy units have considerable potential to contribute to this vital shift in self-identity.

Purcell (in Miller \& Baker, 2008, p. 16) suggests that instability and change within the cultural sphere means that 'music students cannot predict their career paths, and conservatoires must redefine their identities'. This redefinition does not entail dismantling what they have already, but providing opportunities and the structure within which students can freely and without hierarchical inference explore possible selves. Implications include rethinking initial education classes to focus more on the adoption and development of teaching and career 
identities within a holistic framework, questioning the myth of artist as creator without dispelling students’ dreams and ambitions. In closing I return once more to Kagan (1992, p. 164), who suggests that 'classroom teaching appears to be a peculiar form of self-expression in which art, artist, the subject, and the medium are one'. Perhaps this is a Utopian view, but for both classroom and studio music teachers it is one to which we can aspire.

\section{References}

Bain, A. (2005). Constructing an artistic identity. Work Employment Society, 19(25), 25-46.

Beattie, M. (2000). Narratives of professional learning: Becoming a teacher and learning to teach. Journal of Educational Enquiry, 1(2), 1-23.

Bowman, W. Cognition and the body: Perspectives from music education. In L. Bresler (Ed.), Knowing bodies, moving minds: Towards embodied teaching and learning. Norwell, MA: Kluwer Academic Publishers.

Brand, M., \& Dolloff, L. (2002). Fantasies and other romanticized concepts of music teaching: A crosscultural study of Chinese and North American music education students' images of music teaching. International Journal of Music Education, 39(1), 17-30.

Bridgstock, R. (2005, October). What influences the decision to teach? A quantitative application of the Systems Theory Framework of career development. Paper presented at the New Researchers for New Times Conference, Brisbane.

Britton, J. N. (1977). The third area where we are most ourselves: The role of fantasy. In M. Meek (Ed.), The Cool Web (pp. 40-47). London: Bodley Head.

Bruner, J. (1987). Actual minds, possible worlds. Cambridge, MA: Harvard University Press.

Burt-Perkins, R. (2008). Students at a UK conservatoire of music: Working towards a diverse employment portfolio? In D. Bennett and M. Hannan (Eds.), Inside outside downside up: Conservatoire training and musicians’ work. Perth: Black Swan Press.

Burt, R., \& Mills, J. (2006). Taking the plunge: The hopes and fears of students as they begin music college. British Journal of Music Education, 23(1), 51-73. 
Calderhead, J., \& Robson, M. (1991). Images of teaching: Student teachers’ early conceptions of classroom practice. Teaching and Teacher Education, 7(1), 1-8.

Carruthers, G. (2008). Educating professional musicians: Lessons learned from school music. International Journal of Music Education, 26(2),127-135.

Creme, P. (2008). A space for academic play: Student learning journals as transitional writing. Arts and Humanities in Higher Education, 7(49), 49-64.

Ellis, J. (1998). Introduction: The teacher as interpretive inquirer. In J. Ellis (Ed.), Teaching from understanding: Teacher as interpretive inquiry. London: Taylor and Francis.

Eraut, M. (1985). Knowledge creation and knowledge use in professional contexts. Studies in Higher Education, 10(2), 117-33.

Gibbs, P., Angelides, P., \& Michaelides, P. (2004). Preliminary thoughts on a praxis of higher education teaching. Teaching in Higher Education, 9(2), 183-194.

Greene, F. J., \& Saridakis, G. (2008). The role of higher education skills and support in graduate selfemployment. Studies in Higher Education, 33(6), 653-672.

Hargreaves, D. J., \& Marshall, N. A. (2003). Developing identities in music education. Music Education Research, 5(3), 263-273.

Harré, R. (1984). Personal being: A theory for individual psychology. Cambridge, MA: Harvard University Press.

Huhtanen, K. (2008, August). Identity work as a tool in constructing professional identity. Paper presented at the 4th EARLI SIG 14 Learning and Professional Development Conference, U n iversity of Jyväsky lä, $F$ in land.

Huhtanen, K. (2004). Once I had a promising future (facing reality as an ex-promising pianist). Australian Music Forum, 10(3), 21-27.

Kagan, D. (1992). Professional growth among preservice and beginner teachers. Review of Educational Research, (62), 129-169.

Loughran, J. J. (2006). Developing a pedagogy of teacher education: Understanding teaching and learning about teaching. London: Routledge.

McNiff, S. (1997). Art therapy: A spectrum of partnerships. The Arts in Psychotherapy, 24(1), 37-44. 
MacPhail, A., \& Kinchin, G. (2004). The use of drawings as an evaluative tool: Students’ experiences of sport education. Physical Education and Sport Pedagogy, 9(1), 87-108.

Marcus, H., \& Nirius, P. (1986). Possible selves. American Psychologist, 41(9), 954-969.

Miller, J., \& Baker, D. (2007). Career orientation and pedagogical training: Conservatoire undergraduates’ insights. British Journal of Music Education, 24(1), 5-19.

Mills, J., Burt, R., \& Moore, H. (2005). 'Professional performer' - or 'professional musician?’ In Proceedings of 'Performance Matters! International Conference on Practical, Psychological, Philosophical and Educational Issues in Musical Performance (CD). Porto, Portugal: Escola Superior de Educação.

Mills, J., \& Smith, J. (2003). Teachers’ beliefs about effective instrumental teaching in schools and higher education. British Journal of Music Education, 20(1), 5-27.

Presland, C. (2005). Conservatoire students and instrumental professor: The student perspective on a complex relationship. British Journal of Music Education, 22(3), 237-48.

Rogers, R. (2002). Creating a land with music. London: Youth Music.

Ryan, K. (1986). The induction of new teachers. Bloomington, IN: Phi Delta Kappa Educational Foundation.

Van Meter, P., \& Garner, J. (2005). The promise and synthesis of learner-generated drawings: Literature review and synthesis. Educational Psychology Review, 17(4), 285-325.

Van Tilburg, E. (1987). Evaluation with a new twist. Using children’s drawings to gather information. Journal of Extension, 25, 5-7.

Weber, C., \& Mitchell, C. (1995). That's funny, you don't look like a teacher. Cornwall: The Falmer Press.

Word count: 5,851 excluding abstract and references 